\title{
СОЦИОКУЛЬТУРНЫЕ ФАКТОРЫ И ИХ ВЛИЯНИЕ НА ФОРМИРОВАНИЕ РЕЧИ ОБУЧАЮЩИХСЯ КОРЕННЫХ МАЛОЧИСЛЕННЫХ НАРОДОВ СЕВЕРА
}

\section{SOCIO-CULTURAL FACTORS AND THEIR INFLUENCE ON THE FORMATION OF SPEECH OF STUDENTS OF INDIGENOUS MINORITIES OF THE NORTH}

\section{A. Ivanova}

Summary: In multilingual Russia, the native languages of the Russian peoples function together with the state Russian language, some of which are endangered, for example, the languages of the small indigenous peoples of the North. The Russian regions where these peoples live compactly strive to revive and preserve their languages. In this process, the role of the education system is of paramount importance. The author considers the socio-cultural factors that influence the formation of speech of students of educational organizations located in the places of residence of indigenous peoples of the North.

Keywords: peoples of the North, socio-cultural factors, written and oral speech. осударственная поддержка сбалансированного функционирования русского языка как языка межнационального общения и родных языков народов страны - это необходимое условие социально-экономического развития и залог национальной безопасности общества в многонациональной стране, какой является Российская Федерация. «Вопросы сохранения и развития русского, всех языков нашей страны имеют важнейшее значение для гармонизации межнациональных отношений, обеспечения гражданского единства, укрепления государственного суверенитета и целостности России» [1].

Российская Федерация не только одно из поликультурных, но и полиязычных государств мира, так как в нем, по предварительным данным Института языкознания РАН, насчитывается 153 языка, из которых использовались в качестве средства обучения 27 языков (с учетом русского) и изучались как предмет 72 языка [3]. Особую уязвимость испытывают языки, находящиеся под угрозой исчезновения, к таковым относятся и некоторые языки коренных малочисленных народов Севера. Язык живой, пока есть его носители.

Республика Саха (Якутия) - одно из многонациональных регионов России, на территории которого прожива-
Иванова Алёна Васильевна

К.п.н., в.н.с., ФГБНУ «Научно-исследовательский Институт национальных школ Республики Саха-Якутия»

alivv@yandex.ru

Аннотация: В многоязычной России совместно с государственным русским языком функционируют родные языки российских народов, некоторые из которых находятся под угрозой исчезновения, например, языки коренных малочисленных народов Севера. Регионы, где компактно проживают эти народы, стремятся возродить и сохранить их языки. В данном процессе роль системы образования имеет первостепенное значение. Автором рассматриваются социокультурные факторы, влияющие на формирование речи обучающихся образовательных организаций, расположенных в местах проживания коренных малочисленных народов Севера.

Ключевые слова: народы Севера, социокультурные факторы, письменная, устная речь.

ют 5 представителей коренных малочисленных народов Севера, чьи языки Конституцией республики наравне с государственными (русским и языком саха) признаны официальными в местах их компактного проживания [2].

«Язык - это средство общения, средство выражения мыслей. Разумеется, у него есть и другие функции, но эти две - самые основные. Язык служит коммуникации, это самый главный, самый эксплицитный, самый официальный и социально признанный из всех видов коммуникативного поведения» [5, с. 11].

Вклад социокультурных факторов в процесс формирования письменной и устной речи на любом языке значителен. Теоретико-методологической основой данного исследования являются научные разработки в области социокультуры (социальной культуры), которая представляет собой самостоятельное междисциплинарное направление. Теоретическую основу исследования в области социокультуры, рассматривающей взаимодействие культурных и социальных факторов составили труды Е.В. Швачко, М.Е. Дуранова, Л.Н. Когана, А.С. Карминой, П.А. Сорокина, А.Д. Жарковой, С.И. Григорьевой, Л.Г. Гусляковой, И.В. Мерзляковой, А.С. Ахиезер, Л.Г. Ионина, Л.Г. Сокурянской и др. 
Например, ключевыми аспектами социокультурного явления, по мнению П.А. Сорокина, являются общество, культура, личность [7]. Он под «социокультурным» понимал все то, что «люди получают от других людей благодаря непрекращающемуся взаимодействию с культурой как носителем надорганических ценностей». В качестве «надорганических ценностей» в данном случае понимаются все производные сознания человека (язык, наука и философия, религия, искусство, право, этика, нравы, манеры, технические изобретения и т.п.) [4].

В культурологии, социологии, социальной педагогике используются термины «социальная культура», «социокультура», «социально-культурная деятельность», «социокультурная деятельность», «социокультурное развитие», которые нередко заменяются друг другом для обозначения одного и того же понятия [6].

В связи с тем, что эти понятия в науке появились сравнительно недавно, в настоящее время не существует общепризнанного определения.

На основе изучения имеющихся подходов к данным понятиям нами было уточнено базовое понятие и выведена формулировка его определения. Таким образом, социокультурный фактор нами рассматривается как совокупность традиций, обычаев, жизненных ценностей, общественной среды, влияющих на языковую личность.

С целью выявления социокультурных факторов, влияющих на формирование письменной и устной речи на русском языке у обучающихся 8-9 классов сельских об- разовательных организаций, расположенных в местах проживания коренных малочисленных народов Севера, Сибири и Дальнего Востока Российской Федерации, нами проведено исследование в рамках выполнения государственного задания Министерства просвещения РФ ФГБНУ «Научно-исследовательский институт национальных школ Республики Саха (Якутия)» в 2020 году.

Объектом исследования является процесс формирования устной и письменной речи на русском языке обучающихся 8-9 классов сельских общеобразовательных организаций, расположенных в местах проживания коренных малочисленных народов Севера Республики Саха (Якутия).

Предметом исследования выступают социокультурные факторы, влияющие на формирование письменной и устной речи на русском языке у обучающихся 8-9 классов коренных малочисленных народов Севера.

Исследование проводилось при помощи эмпирических методов: анкетирование, изучение школьной документации, образовательных (творческих) продуктов обучающихся. Использование методов анкетирования в дистанционном формате (Google forma) обусловлено тем, что исследование было проведено в апреле-мае 2020 г. в условиях ситуации, связанной с пандемией.

База исследования. Для выявления указанных факторов всего исследованием было охвачено 44 респондента, из них - 26 учащихся 8-9 классов, 6 учителей русского языка и 12 родителей из 3 сельских общеобразовательных организаций, расположенных в местах проживания

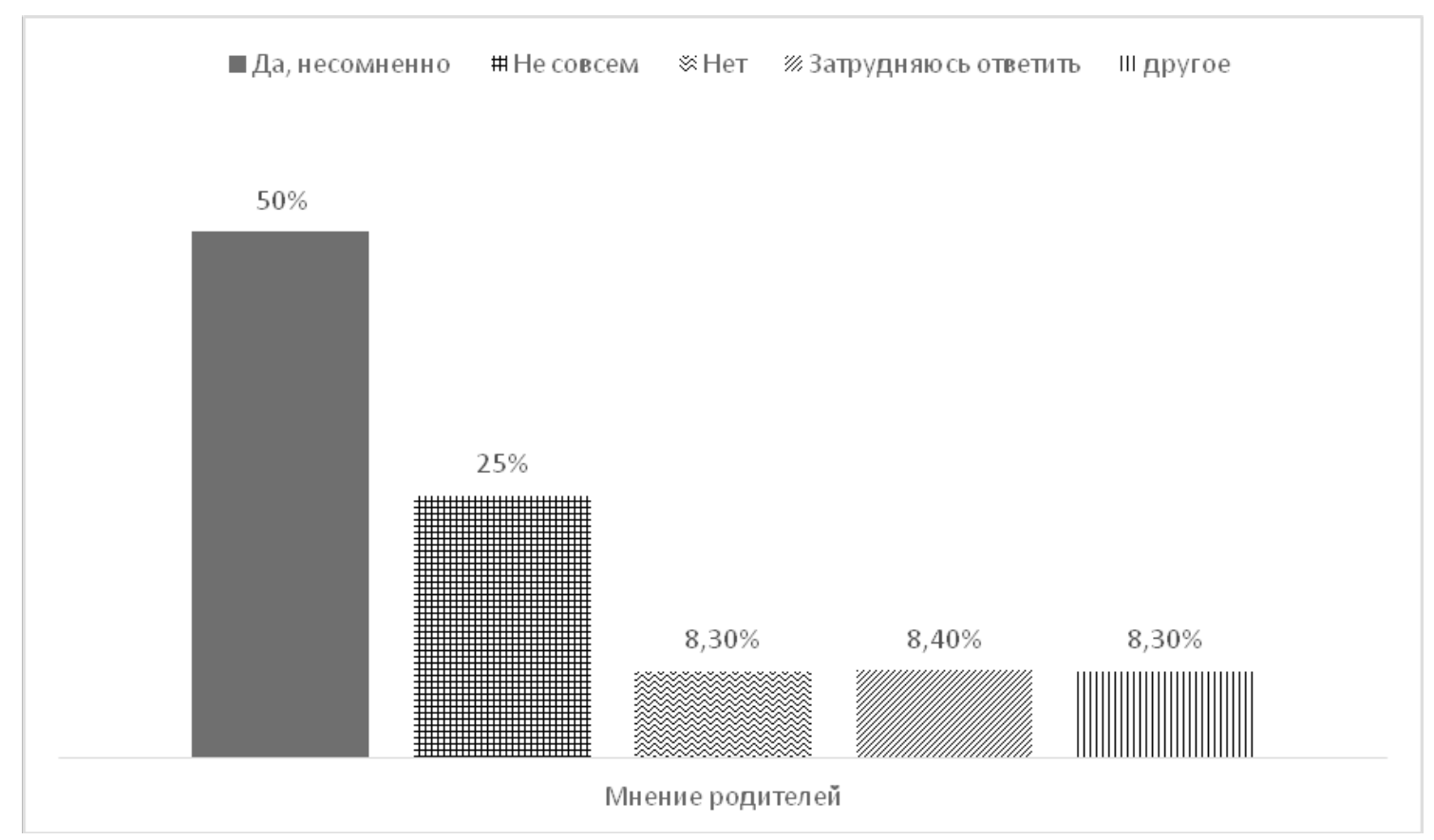

Рис. 1. Мнение родителей. 


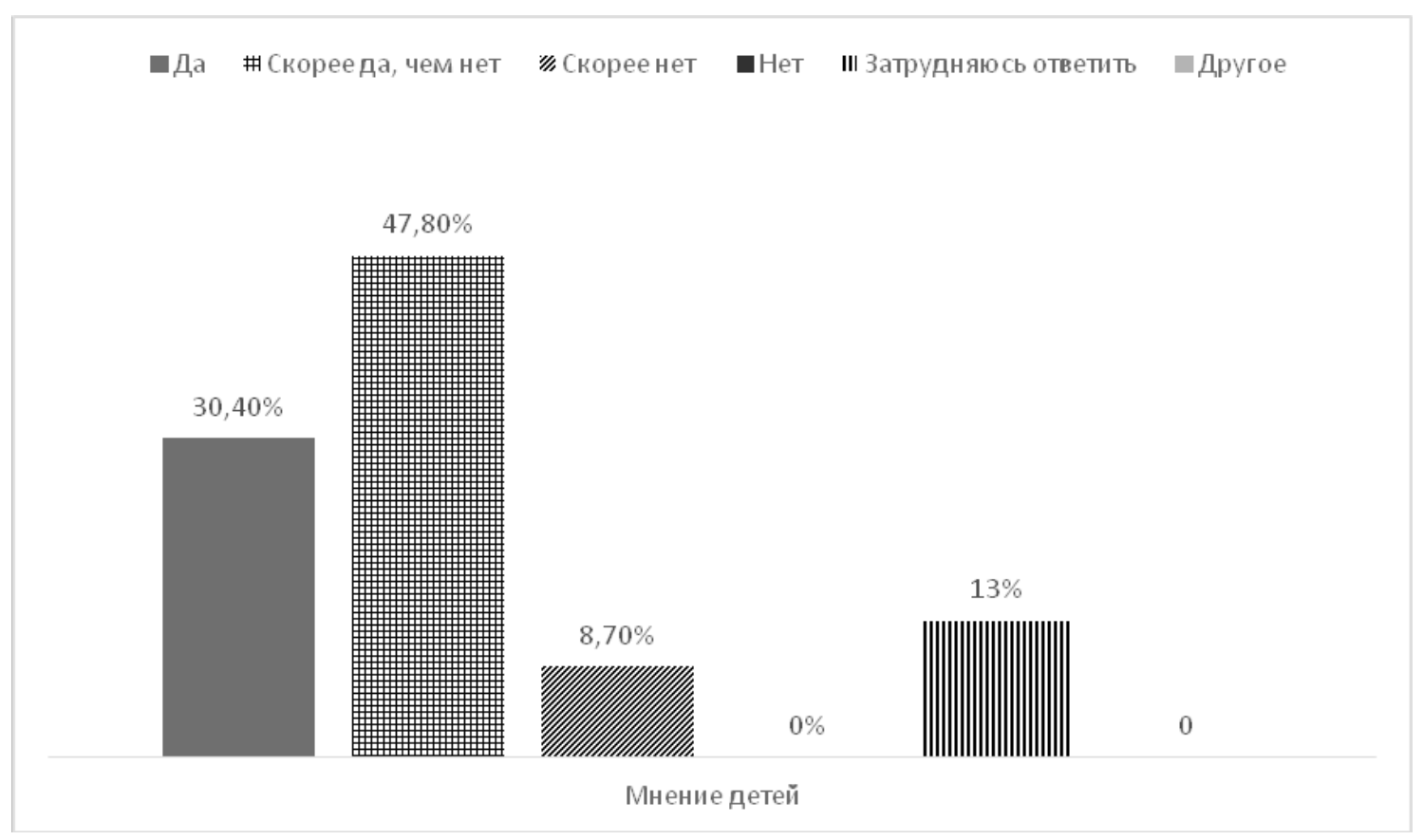

Рис. 2. Мнение детей.

коренных малочисленных народов Севера: Кобяйском, Олекминском, Анабарском районах Республики Саха (Якутия). Критерием отбора (выборки) участников - образовательных организаций - стало изучение языков коренных малочисленных народов Севера в школе. Для объективности результатов к проведению исследования были привлечены школы по языкам обучения коренных малочисленных народов Севера: эвенский, эвенкийский, долганский. Для трех групп респондентов были подготовлены три разные виды анкет: для учителей русского языка, учащихся и их родителей. Также для учащихся были предложены письменные задания, направленные на выявление уровня письменной речи на русском языке. Задания носили этнокультурный характер, т.е. в них был включен материал о представителях коренных малочисленных народов Севера, родных языках, отрывки из произведений не только классиков русской литературы, но и писателей северных народов, в данном случае эвенского и эвенкийского народов.

Как свидетельствуют результаты проведенного исследования, по мнению $100 \%$ учителей, именно школа больше способствует формированию грамотной письменной и устной речи на русском языке у обучающихся.

По мнению 50\% родителей, уровень письменной и устной речи на русском языке существенно отличается от места проживания: город/село.

Точку зрения 25\% родителей разделяют 47,8\% детей, считающих, что уровень речи на русском языке отличался бы, если бы они жили в городе.
66\% отмечают также роль семьи, школьных, сельских библиотек и СМИ. 100\% родителей указывают первостепенное влияние уроков русского языка, свыше 80\% - участие с докладами в научно-практических конференциях, 75\% - различных конкурсах, например, выразительного чтения, ораторского мастерства. Свыше $83 \%$ учителей среди причин, мешающих развитию грамотной речи детей, назвали низкую мотивацию к чтению художественной литературы.

Проблема мотивации к чтению остается весьма актуальной: 41\% родителей ответили, что читают вместе с детьми книги на русском языке только иногда, время от времени, по 25\% - что не читают вовсе или затруднились с ответом на данный вопрос. $45 \%$ учащихся читают только то, что им задают на уроках, 35\% - 1 книгу в месяц. По мнению учителей, дети вне школьной программы читают фантастическую, приключенческую литературу, при этом отдавая предпочтение зарубежной. Среди языков, на которых предпочитают читать дети, преобладает русский язык, затем идут родные и якутский языки. Большей частью дети предпочитают чтение в бумажном формате, чем электронном, что объяснимо скорей всего спецификой сельской местности, где очень слабая скорость интернета. Для 44\% учащихся, что составляет наибольший процент, именно художественная литература служит образцом грамотной речи на русском языке, далее отмечены речь учителя в школе и интернет, социальные сети (24\%). 100\% родителей разделяют мнение своих детей по поводу художественной литературы, 66\% - речи учителей в качестве образца. 
Из средств связи, которыми активно пользуются учащиеся, они выделили: WhatsAp (75\%), Instagram $(50 \%)$,YouTube $(45 \%)$, ВКонтакте (33\%), которые, по их мнению, помогают грамотнее говорить по-русски. Учителя почти солидарны со своими учащимися в данном вопросе: 83\% считают YouTube, по 66\% Instagram и WhatsAp помощниками в формировании грамотной речи у обучающихся. Данный факт приобретает особую актуальность в связи с пандемией коронавируса, когда вся образовательная деятельность перешла на дистанционный формат и данные средства связи выступают своего рода посредниками этого процесса. А родители влияние интернета и социальных сетей отмечают в качестве отрицательного фактора. Половина опрошенных учителей подчеркивает, что увлечение интернетом и социальными сетями создает препятствия формированию грамотной речи, также к таким причинам отнесли употребление ненормативной лексики, жаргонов. 25\% детей не скрывают, что употребляют в своей речи такие слова, 25\% употребляют, но редко, 25\% стараются избегать использования таких слов, 20\% не используют.

Ограниченное развитие языковой среды на русском языке в сельской местности $83 \%$ учителей отметили как причину, мешающую формированию грамотной речи у детей. Если проанализировать, на каком языке чаще общаются дети, то общение на русском наблюдается только во время уроков русского языка, после уроков: во время внеурочных мероприятий, в магазине, библиотеке, больнице - общаются на родных языках. Но языком общения детей с людьми старшего поколения, со своими сверстниками, с детьми младшего возраста выступает якутский язык. По поводу уровня владения русским языком в селе $83 \%$ учителей считают, что взрослое население владеет на бытовом уровне общения, 16\% отметили частичное владение (понимают, но говорят с ошибками). Родители среди учреждений, которые проводят достаточную работу по популяризации русского языка на селе, 100\% отметили школу, 66\% - сельскую библиотеку, крайне низкие проценты (8\%) в этом процессе отведены: местной администрации, общественным организациям (клубы по интересам, ассоциации и др.). Для 91\% родителей умение грамотно излагать свои мысли на русском языке необходимо для дальнейшего поступления на учебу и престижной работы после ее окончания (58\%), также для получения знаний в школе (66\%). Из трех языков (родной, русский, иностранный) овладение русским языком считают наиболее важным для своих детей 100\% родителей, далее идут родной и иностранный языки. Для 95\% учащихся наиболее востребованным в современном обществе является русский язык, 78\% считают, что это английский и $56 \%$ отдают предпочтение родному языку.

Таким образом, можно сделать вывод, что в сельских местностях Республики Саха (Якутия), где проживают представители коренных малочисленных народов Севера, преимущественно наблюдается языковая среда на родных и якутском языках, т.е. на официальных и государственном языках республики.

По показателям социокультурного фактора наблюдается низкая мотивация к чтению художественной литературы учащимися в школе и семье, являющаяся препятствием к формированию письменной и устной речи на русском языке. Одной из причин угасания интереса к чтению указывают увлечение интернетом, социальными сетями, что, по мнению родителей, является фактором, мешающим формированию грамотной речи у детей.

Также своего рода препятствием для развития устной речи может служить ограниченная языковая среда на русском языке в условиях сельского социума. По итогам исследования языком общения в селах, расположенных в местах проживания коренных малочисленных народов Севера, преимущественно является якутский язык, являющийся государственным языком республики. Представители коренных малочисленных народов Севера Якутии живут в условиях функционирования многоязычия (трехъязычия): родной, русский, якутский языки.

Также следует отметить, что, с точки зрения не только родителей, но и самих учащихся, русский язык является показателем уровня образованности в качестве наиболее востребованного языка в современном обществе, например, на фоне возрастания интереса к изучению иностранных языков. Отрадно, что при этом наличие мотивации к изучению родного языка также отмечается всеми респондентами.

Предварительные результаты исследования служат основанием для некоторых рекомендаций, направленных на формирование письменной и устной речи на русском языке у обучающихся 8-9 классов сельских образовательных организаций, расположенных в местах проживания коренных малочисленных народов Севера. В качестве рекомендаций следует указать, что необходимо:

- проводить работу по развитию устной формы речи на русском языке: организовывать участие детей с выступлениями на научно-практических конференциях, выезды за пределы села для участия в различных мероприятиях;

- для усиления мотивации к чтению художественной литературы повысить роль читательского интереса, начиная с организации семейного чтения;

- в целях развития языковой среды привлечь к работе по популяризации русского языка в условиях села не только школу как социокультурный центр, но и общественные организации (ассоциации, клубы по интересам);

- использовать благоприятные возможности со- 
временных цифровых (информационных) технологий, в том числе социальных сетей, для развития письменной и устной речи школьников.

Надо отметить, что полученные результаты позволили выявить социокультурные факторы и их влияние на формирование письменной и устной речи обучающихся. Для определения более полной картины исследования в перспективе необходимо выявление и других факторов, например, этнолингвистических, социолингвистических, лингводидактических, психолого-педагогических и др.

\section{ЛИТЕРАТУРА}

1. Из выступления В. Путина 19 мая 2015 года на совместном заседании Совета по межнациональным отношениям и Совета по русскому языку [Электронный ресурc]: URL: www.kremlin.ru (дата обращения: 21.06.2020).

2. Конституция (Основной закон) Республики Саха (Якутия) (с изменениями и дополнениями) [Электронный ресурс]: URL: https://constitution.garant.ru/ region/cons_saha/ (дата обращения: 17.06.2020).

3. Раздел «Языки России» сайта Института языкознания РАН [Электронный ресурс]: URL: https://iling-ran.ru/web/ru/jazykirf (дата 0бращения: 9.07.2020).

4. Сорокин П.А. (2006) Социокультурная динамика и эволюционизм / Американская социологическая мысль. М.: МУБП, 1996. - С. 372-392.

5. Тер-Минасова. Язык и межкультурная коммуникация: учебное пособие для студентов, аспирантов и соискателей. М.: Слово, $2000 .-165$ с.

6. Швачко Е.В., Дуранов М.Е. Аспектный подход к социокультурному развитию личности [Электронный ресурс] // Современная высшая школа: инновационный аспект, 2014. №2. URL: https://cyberleninka.ru/article/n/aspektnyy-podhod-k-sotsiokulturnomu-razvitiyu-lichnosti (дата 0бращения: 01.06.2020).

7. Sorokin P.A. Social and cultural dynamics: A study of change in major systems of art, truth, ethics, law, and social relationships. - New Brunswick (NJ): Transaction publishers, 1995. - P. 547.

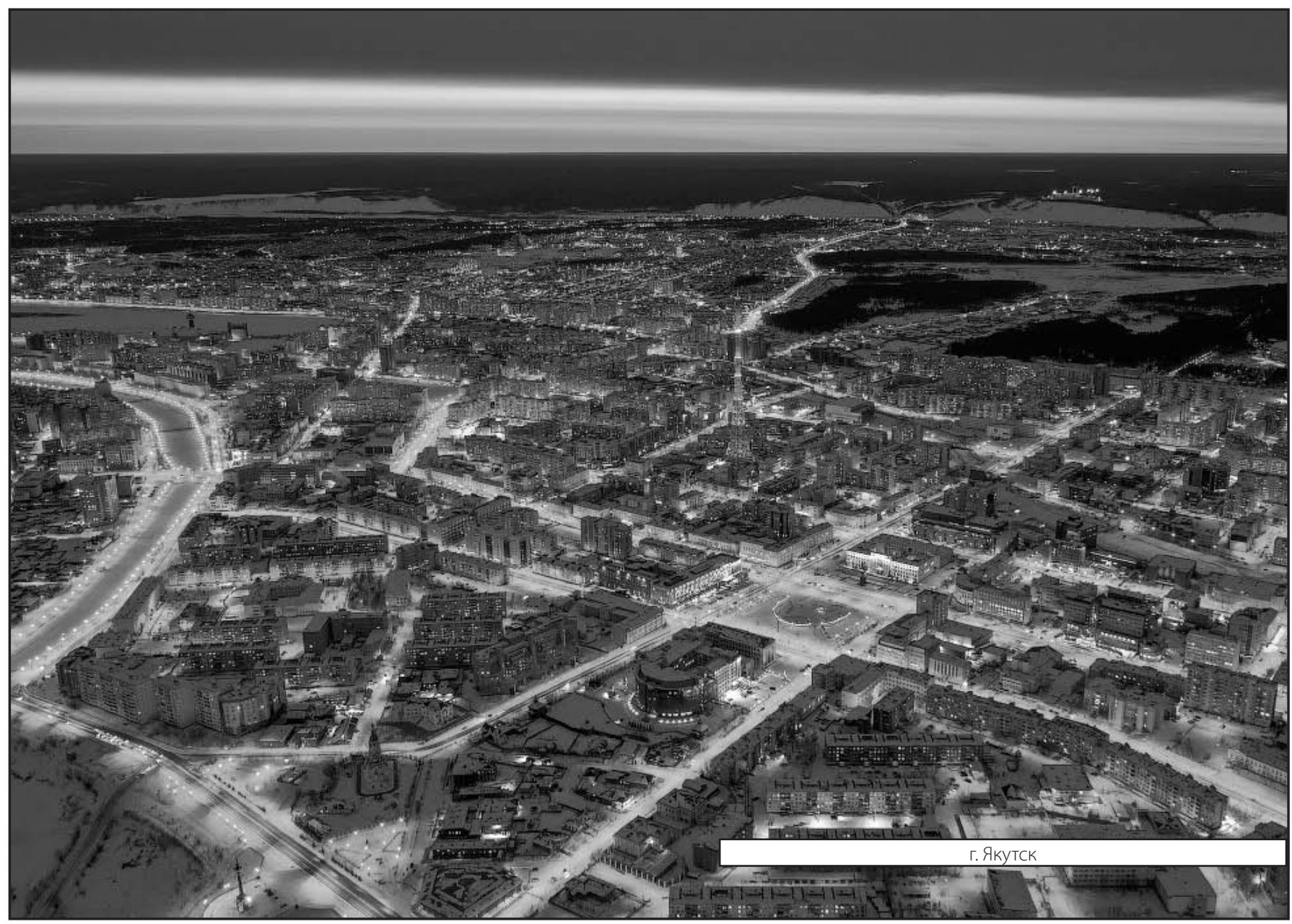

